See Article page 1080.

\section{Commentary: Management of congenitally corrected transposition: Different strokes for different folks}

\author{
Joseph B. Clark, MD
}

Congenitally corrected transposition of the great arteries (CCTGA) is a rare diagnosis consisting of combined atrioventricular and ventriculoarterial discordance with the morphologic right ventricle (mRV) and tricuspid valve within the systemic circulation. Historically, patients were managed with either observation or surgery to treat associated pathology, such as ventricular septal defect or pulmonary stenosis. This physiologic repair left the mRV and tricuspid valve to support the systemic workload. Recognizing the risks of progressive $\mathrm{mRV}$ dysfunction and tricuspid regurgitation, operations were pioneered to restore the morphologic left ventricle $(\mathrm{mLV})$ and mitral valve to the systemic circulation. ${ }^{1}$ Many centers have subsequently adopted this anatomic repair strategy as the preferred approach. ${ }^{2-7}$

In this issue of the Journal, Barrios and colleagues ${ }^{7}$ present one of the largest, most diverse series of patients with CCTGA reported to date. The review includes 5 cohorts in distinctively different age groups: young children managed with anatomic repair or Fontan palliation and adults managed with physiologic repair, observation, or primary transplantation.

For adults who presented with preserved function and without associated lesions, simple observation was a successful option; the prototypical noninterventional patient presented at a median age of 35 years and demonstrated a further 20 -year survival of $88 \%$. As the authors note, this apparent excellent long-term survival

From the Division of Pediatric Cardiac Surgery, Department of Pediatrics, Penn State Children's Hospital, Hershey, Pa.

Disclosures: The author reported no conflicts of interest.

The Journal policy requires editors and reviewers to disclose conflicts of interest and to decline handling or reviewing manuscripts for which they may have a conflict of interest. The editors and reviewers of this article have no conflicts of interest.

Received for publication Nov 25, 2020; revisions received Nov 25, 2020; accepted for publication Nov 30, 2020; available ahead of print Dec 5, 2020.

Address for reprints: Joseph B. Clark, MD, Division of Pediatric Cardiac Surgery, Department of Pediatrics, Penn State Children's Hospital, 500 University Drive, H085, Hershey, PA 17033 (E-mail: jclark7@ pennstatehealth.psu.edu).

J Thorac Cardiovasc Surg 2021;161:1094-5

0022-5223/\$36.00

Copyright (c) 2020 by The American Association for Thoracic Surgery

https://doi.org/10.1016/j.jtcvs.2020.11.146

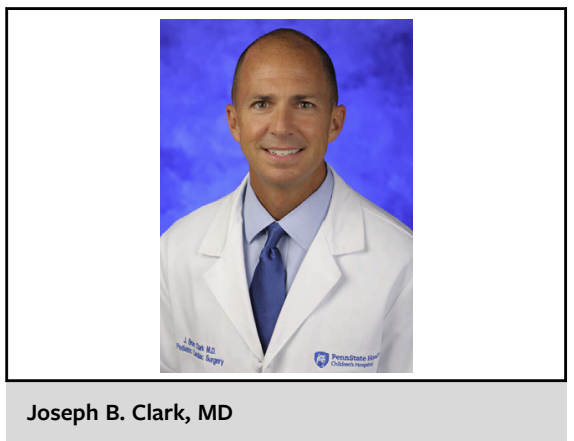

\author{
CENTRAL MESSAGE \\ Although anatomic repair is a \\ favored approach for the man- \\ agement of congenitally cor- \\ rected transposition, \\ conclusively demonstrating the \\ superiority of this pathway re- \\ mains difficult.
}

may have benefited from both an unknown denominator and transition into the physiologic repair or transplant cohorts. For adults presenting with residual lesions, operative intervention usually occurred within a few years; this prototypical patient underwent physiologic repair at age 25 years and had a 15 -year survival of $71 \%$. Finally, for patients presenting with end-stage heart failure, primary heart transplantation represented the last resort and occurred at a median age of 46 years. Thus, most patients who presented in adulthood were managed primarily with observation or physiologic repair and survived well into middle age.

Among the children, a minority presented early with anatomy not amenable to biventricular repair and were directed toward Fontan palliation with excellent outcomes, similar to other studies. ${ }^{8}$ For the large majority of children, anatomic repair was the strategy of choice, with preparatory $\mathrm{mLV}$ training as needed. The anatomic repair group showed several positive outcomes. Most anatomic repair patients demonstrated preserved systemic ventricular function, in contrast to the physiologic repair patients. Patients who required $\mathrm{mLV}$ training or underwent repair at an older age did not show worse outcomes, unlike in other studies. ${ }^{4,5}$ Finally, these patients demonstrated very good survival $(80 \%$ at 15 years), consistent with other encouraging reports. $^{2-6}$ 
For young children with favorable anatomy, the authors, like others, advocate for anatomic repair whenever feasible. However, they are reluctant to offer a universal recommendation for anatomic repair. Instead, they advise this strategy for patients with good biventricular and atrioventricular valve function. Although anatomic repair has become a favored choice, and the supporting rationale is sensible, intuitive, and backed by accumulating experience, there remains some room for equipoise. As this study shows, there was no clear winner among the multiple treatment pathways for this complex and heterogeneous disease.

\section{References}

1. Ilbawi MN, DeLeon SY, Backer CL, Duffy CE, Muster AJ, Zales VR, et al. An alternative approach to the surgical management of physiologically corrected transposition with ventricular septal defect and pulmonary stenosis or atresia. J Thorac Cardiovasc Surg. 1990;100:410-5.
2. Shin'oka T, Kurosawa H, Imai Y, Aoki M, Ishiyama M, Sakamoto T, et al Outcomes of definitive surgical repair for congenitally corrected transposition of the great arteries or double outlet right ventricle with discordant atrioventricular connections: risk analyses in 189 patients. J Thorac Cardiovasc Surg. 2007;133: 1318-28. e1-4.

3. Murtuza B, Barron DJ, Stumper O, Stickley J, Eaton D, Jones TJ, et al. Anatomic repair for congenitally corrected transposition of the great arteries: a singleinstitution 19-year experience. J Thorac Cardiovasc Surg. 2011;142:1348-57.e1.

4. Bautista-Hernandez V, Myers PO, Cecchin F, Marx GR, del Nido PJ. Late lef ventricular dysfunction after anatomic repair of congenitally corrected transposition of the great arteries. J Thorac Cardiovasc Surg. 2014;148:254-8.

5. Brizard CP, Lee A, Zannino D, Davis AM, Fricke TA, d'Udekem Y, et al. Long-term results of anatomic correction for congenitally corrected transposition of the great arteries: a 19-year experience. J Thorac Cardiovasc Surg. 2017;154:256-65.e4.

6. Hraska V, Vergnat M, Zartner P, Hart P, Suchowerskyj P, Beirbach B, et al. Promising outcome of anatomic correction of corrected transposition of the great arteries. Ann Thorac Surg. 2017;104:650-6.

7. Barrios PA, Zia A, Pettersson G, Najm HK, Rajeswaran J, Bhimani S, et al Outcomes of treatment pathways in 240 patients with congenitally corrected transposition of great arteries. J Thorac Cardiovasc Surg. 2021;161:1080-93.e4.

8. Hraska V, Duncan BW, Mayer JE Jr, Freed M, del Nido PJ, Jonas RA. Long-term outcome of surgically treated patients with corrected transposition of the great arteries. J Thorac Cardiovasc Surg. 2005;129:182-91.
See Article page 1080.

\section{Commentary: Incomplete data and inertia: Neither silences the tolling bell of corrected transposition}

\author{
Ronald K. Woods, MD, PhD, and \\ Viktor Hraska, MD, PhD
}

Barrios and colleagues have taken on a truly massive effort with the ultimate goal of improving our understanding of the long-term outcomes associated with various treatment

\footnotetext{
From the Division of Pediatric Cardiothoracic Surgery, Department of Surgery, Herma Heart Institute, Children's Wisconsin, Medical College of Wisconsin, Milwaukee, Wis.

Disclosures: The authors reported no conflicts of interest.

The Journal policy requires editors and reviewers to disclose conflicts of interest and to decline handling or reviewing manuscripts for which they may have a conflict of interest. The editors and reviewers of this article have no conflicts of interest.

Received for publication Nov 18, 2020; revisions received Nov 18, 2020; accepted for publication Nov 19, 2020; available ahead of print Dec 1, 2020.

Address for reprints: Ronald K. Woods, MD, PhD, Division of Pediatric Cardiothoracic Surgery, Department of Surgery, Children's Wisconsin, Medical College of Wisconsin, 9000 W Wisconsin Ave, MS B 730, Milwaukee, WI 53226 (E-mail: rwoods@chw.org).

J Thorac Cardiovasc Surg 2021;161:1095-6

$0022-5223 / \$ 36.00$

Copyright (c) 2020 by The American Association for Thoracic Surgery

https://doi.org/10.1016/j.jtcvs.2020.11.095
}

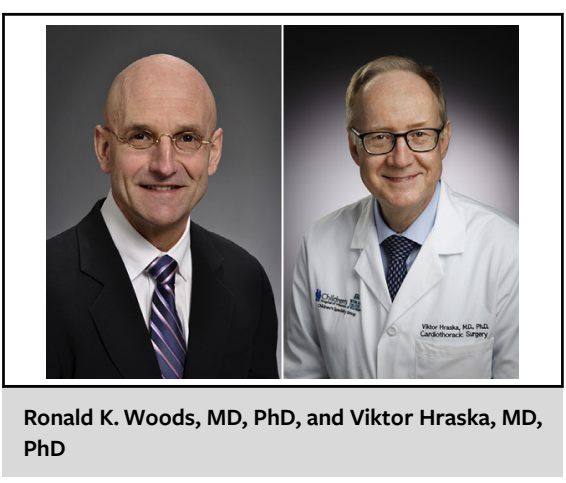

CENTRAL MESSAGE

The Cleveland Clinic's report on corrected transposition offers very interesting reading but lacks convincing data to provide new insight into optimal management strategies.

strategies for corrected transposition of the great arteries (cTGA). They have capitalized on both statistical expertise and a large cohort spanning the interval from 1995 to 2000. We applaud them for their effort and hard work and also express our respect and gratitude to Dr Roger Mee. 